\title{
PERAN TENAGA KESEJAHTERAAN SOSIAL KECAMATAN KOTA KENDARI DALAM PEMBERDAYAAN POTENSI WANITA RAWAN SOSIAL EKONOMI
}

\author{
Hasmi $^{1}$, Juhaepa ${ }^{2}$, Ambo Upe ${ }^{3}$ \\ ${ }^{1}$ Jurusan Ilmu Kesejahteraan Sosial FISIP Universitas Halu Oleo Kendari, Indonesia \\ ${ }^{2}$ Jurusan Sosiologi FISIP Universitas Halu Oleo Kendari, Indonesia \\ ${ }^{3}$ Jurusan Sosiologi FISIP Universitas Halu Oleo Kendari, Indonesia \\ hasmiemi29@gmail.com
}

\begin{abstract}
The study aims to 1) to find out the role of sub-district social welfare staff in empowering the potential of women with socio-economic vulnerability, 2) to find out the supporting and inhibiting factors in the implementation of the role of the social welfare staff in the district of Kendari in empowering in socioeconomic vulnerability. The data analysis used was a qualitative analysis with the number fifteen people consisting of four sub-district social welfare workers, eight socioeconomic women, one social services secretary, one staff database holder, while the data sources used are primary data and secondary data. As for the data collection techniques used are observation, interview and documentation techniques. The results showed that there were several roles of sub-district social welfare staff in empowering the potential for socio-economic vulnerable women, namely 1) data collection and validation, 2) looking for potential, 3) coordination with social services, 4) implementation of social welfare. As for the supporting factors of social welfare workers in implementing the potential empowerment of women with socioeconomic vulnerability, they are 1) giving authority, 2) motivation, 3) sub-district social welfare workers approaching women with socio-economic vulnerability. While the inhibiting factors of sub-district social welfare staff carrying out empowerment are 1) transportation, 2) dislike of women who are socioeconomic vulnerable.
\end{abstract}

Keywords: role, sub-district social welfare staff, empowerment, women vulnerable to social economy.

\begin{abstract}
ABSTRAK
Penelitian ini bertujuan (1) untuk mengetahui peran tenaga kesejahteraan sosial kecamatan (TKSK) Kota Kendari dalam pemberdayaan potensi wanita rawan sosial ekonomi, (2) untuk mengetahui faktor pendukung dan penghambat pelaksanaan peran tenaga kesejahteraan sosial kecamatan (TKSK) Kota Kendari dalam pemberdayaan potensi wanita rawan sosial ekonomi. Analisi data yang digunakan adalah analisis kualitatif dengan jumlah informan penelitian 15 orang yang terdiri dari 4 Tenaga Kesejahteraan Sosial Kecamatan, 8 Wanita Rawan Sosial Ekonomi, 1 Sekertaris Dinas Sosial, 1 Kepala Bidang Jaminan Sosial, 1 Staf Pemegang Basis Data Terpadu (BDT), sedangkan sumber data yang digunakan adalah data primer dan data sekunder. Adapun tekhnik pengumpulan data yang digunakan adalah tekhnik observasi, wawancara dan dokumentasi. Hasil penelitian menunujukkan bahwa terdapat beberapa peran Tenaga Kesejahteraan Sosial Kecamatan dalam pemberdayaan potensi Wanita Rawan Sosial Ekonomi yaitu 1) Pendataan dan Validasi Data, 2) Mencari Potensi, 3) Koordinasi dengan Pihak Dinas Sosial, 4) Penyelenggaraaan Kesejahteraan Sosial. Adapun faktor pendukung Tenaga Kesejahteraan Sosial Kecamatan dalam melaksanakan pemberdayaan potensi Wanita Rawan Sosial Ekonomi adalah 1) Memberikan Kewenangan, 2) Motivasi, 3) TKSK melakukan pendekatan dengan WRSE. Sedangkan faktor penghambat Tenaga Kesejahteraan Sosial Kecamatan melaksanakan pemberdayaan adalah 1) Transportasi, 2) Ketidakterbukaan WRSE.
\end{abstract}

Kata-Kata Kunci: Peran, TKSK, Pemberdayaan, Wanita Rawan Sosial Ekonomi. 


\section{PENDAHULUAN}

Kemiskinan menjadi masalah yang penting, sehingga menjadi fokus perhatian saat ini di Indonesia. Masalah kemiskinan sangatlah kompleks dan bersifat multidimensional, dimana berkaitan dengan aspek sosial, ekonomi, budaya dan aspek lainnya. Kemiskinan terus menjadi masalah fenomenal didunia, khususnya Indonesia yang merupakan negara berkembang. Kemiskinan yang terjadi memang perlu dilihat sebagai suatu masalah yang sangat serius, karena saat ini kemiskinan membuat banyak masyarakat Indonesia mengalami kesusahan dalam memenuhi kebutuhan hidupnya. Persoalan kemiskinan ini lebih dipicu karena masih banyaknya masyarakat, inilah yang membuat sulitnya dalam memenuhi kebutuhan hidupnya, sehingga angka kemiskinan selalu ada.

Tenaga Kesejahteraan Sosial Kecamatan (TKSK) adalah warga masyarakat yang peduli terhadap Penyandang Masalah Kesejahteraan Sosial (PMKS) dan memiliki wawasan tentang ilmu kesejahteraan sosial dan komitmen terhadap usaha kesejahteraan sosial. Maka Tenaga Kesejahteraan Sosial Kecamatan (TKSK) melakukan pembinaan dalam penyelenggaraan Program Percepatan dan Perluasan Perlindungan Sosial (P4S), Tenaga Kesejahteraan Sosial Kecamatan (TKSK) bekerja dengan arahan dari Kementerian Sosial dan melakukan koordinasi dengan Dinas Sosial Kabupaten/ Kota. Tenaga Kesejahteraan Sosial Kecamatan (TKSK) tidak terkait langsung dengan struktur dalam pemerintah kecamatan tetapi merupakan binaan dari Dinas Sosial dan Kementrian Sosial.

Peran Tenaga Kesejahteraan Sosial Kecamatan dalam memberi pelayanan sosial maupun pemberdayaan sosial kepada Wanita Rawan Sosial Ekonomi (WRSE) tersebut yaitu Tenaga Kesejahteraan Sosial Kecamatan (TKSK) akan lebih banyak berinteraksi dan berkoordinasi dengan unsur pemerintah dan desa/ kelurahan, unit pelaksanaan Program Percepatan dan Perluasan Perlindungan Sosial P4S (Pengelolaan Raskin dan PKH), kantor pos kecamatan, serta masyarakat pada umumnya. Selanjutnya menyediakan informasi mengenai akses sumber kesejahteraan sosial yang tersedia dan prosedur yang diperlukan untuk mempermudah interaksi antara Wanita Rawan Sosial Ekonomi (WRSE) dengan pemilik sumber. Tujuan dan peran tenaga kesejahteraan membina pemberdayaan masyarakat adalah memandirikan masyarakat agar dapat menggunakan dan mengakses sumberdaya yang mereka miliki maksimal mungkin, pada dasarnya pemberdayaan masyarakat adalah sebuah proses yang terus menerus untuk meningkatkan kemampuan dan kemandirian masyarakat mencapai kesejahteraan. 
Dalam hal ini diperlukannya pemberdayaan perempuan melalui pelatihan keterampilan, khususnya pemberdayaan bagi Wanita Rawan Sosial Ekonomi (WRSE). Wanita Rawan Sosial Ekonomi (WRSE) merupakan salah satu kategori dari Penyandang Masalah Kesejahteraan Sosial (PMKS) berkaitan dengan Peraturan Mentri No.8 tahun 2012 tentang Pedoman Pendataan dan Pengelolaan Data Penyandang Masalah Kesejahteraan Sosial (PMKS) dan Potensi dan Sumber Kesejahteraan Sosial (PSKS). Dalam Permensos No. 8 Tahun 2012 menyebutkan bahwa Wanita Rawan Sosial Ekonomi adalah seorang perempuan dewasa menikah, belum menikah, atau janda dan tidak mempunyai penghasilan cukup untuk dapat memenuhi kebutuhan pokok sehari-hari. Selain itu dalam Permensos tersebut juga disebutkan kriteria seseorang digolongkan menjadi wanita rawan sosial ekonomi adalah perempuan berusia delapan belas tahun sampai lima puluh sembilan tahun, merupakan istri yang ditinggal suami tanpa kejelasan, menjadi pencari nafkah utama keluarga, dan berpenghasilan kurang atau tidak mencukupi kebutuhan hidup layak.

Selain faktor kemiskinan yang menjadi penyebab seorang wanita menjadi golongan wanita rawan sosial ekonomi adalah faktor pendidikan dan faktor mental mereka. Dengan pendidikan yang relatif rendah menjadikan mereka kehilangan akal sehatnya dalam mencari cara untuk memenuhi kebutuhan hidupnya. Hal tersebut menyebabkan mereka terjerumus dalam penyimpangan sosial.

Dinas sosial mengemukakan bahwa semua kecamatan yang ada di Kota Kendari telah terdapat Tenaga kesejahteraan sosial (TKSK) sejak tahun 2009, dimana masingmasing dalam satu kecamatan hanya ada satu orang Tenaga Kesejahteraan Sosial Kecamatan yang ditugaskan di Dinas Sosial Kota Kendari. Tenaga Kesejahteraan Sosial Kecamatan (TKSK) tersebut mengunjungi satiap kelurahan atau kecamatan hanya ketika ada permasalahan yang harus ditangani (Sumber Dinas Sosial Kota Kendari).

Untuk data terkait Wanita Rawan Sosial Ekonomi (WRSE) di Kota Kendari, terlihat dari pemberdayaan yang telah dilakukan oleh Dinas Sosial melalui Tenaga Kesejahteraan Sosial Kecamatan (TKSK) adalah program Bantuan Pangan Non Tunai (BPNT), Program Keluarga Harapan (PKH), program Kelompok Usaha Bersama (KUBE), dan program bantuan seperti Rumah Tidak Layak Huni (RTLH). Programprogram tersebut adalah berbagai macam usaha dari Dinas Sosial Kota Kendari untuk melakukan pemberdayaan Wanita Rawan Sosial Ekonomi (WRSE). 


\section{METODE PENELITIAN}

Penelitian ini dilakukan di Kota Kendari mulai bulan Desember-Januari 2020. Jenis penelitian ini merupakan pendekatan kualitatif dengan fokus penelitiannya adalah Peran Tenaga Kesejahtraan Sosial Kecamatan (TKSK) Kota Kendari Dalam Pemberdayaan Potensi Wanita Rawan Sosial Ekonomi (WRSE). Menurut Sugiyono (2009:15), penelitian kualitatif adalah penelitian yang berlandaskan pada filsafat post positivisme, digunakan untuk meneliti pada kondisi obyek yang alamiah (sebagai lawan dari eksperimen) dimana peneliti adalah sebagai instrument kunci. Adapun informan dalam penelitian ini adalah tenaga kesejahteraan sosial kecamatan (TKSK) berjumlah empat orang, wanita rawan sosial ekonomi (WRSE) berjumlah delapan orang, sekertaris Dinas Sosial Kota Kendari satu orang, staf pemegang Basis Data Terpadu (BDT) berjumlah satu orang, kepala bidang Jaminan Sosial satu orang. Metode pengumpulan data yang digunakan adalah observasi, wawancara, dan dokumentasi.

Analisis data dalam penelitian ini, peneliti menggunakan analisis data model Miles dan Hurberman (Upe dan Damsid, 2010): yaitu: Reduksi Data, Penyajian Data, Verifikasi. Adapun langkah-langkah yang peneliti gunakan adalah :Mengumpulkan atau merangkum data yang diperoleh dari proses wawancara dengan pihak untuk dianalisis, Menafsirkan data yang diperoleh, Menarik kesimpulan terhadap apa yang diteliti.

\section{PEMBAHASAN}

\section{Peran Tenaga Kesejahteraan Sosial Kecamatan (TKSK) Kota Kendari Dalam Pemberdayaan Potensi Wanita Rawan Sosial Ekonomi}

\section{Pendataan dan Validasi Data}

Pendataan adalah kegiatan untuk mengumpulkan data dan informasi yang dilakukan oleh Tenaga Kesejahteraan Sosial Kecamatan (TKSK) terhadap Wanita Rawan Sosial Ekonomi (WRSE). Pendataan WRSE bertujuan untuk mengetahui potensi yang dimiliki oleh Wanita rawan sosial ekonomi tersebut.

Validasi basis data terpadu (BDT) sangatlah penting untuk menentukan siapa saja orang-orang yang akan diberikan bantuan.

\section{Mencari Potensi}

Mencari potensi WRSE adalah peran TKSK untuk menentukan potensi apa yang ada pada WRSE agar dana WRSE dapat berguna dengan baik.

\section{Melakukan Koordinasi dengan Pihak Dinas Sosial}


Melakukan koordinasi dengan pihak dinas sosial kota Kendari adalah untuk menjaga, menciptakan, mendukung, dan memperkuat penyelenggaraan kesejahteraan sosial wanita rawan sosial ekonomi (WRSE).

\section{Penyelenggaraan Kesejahteraan Sosial}

Membantu penyelenggaraan kesejahteraan sosial adalah upaya yang terarah, terpadu dan berkelanjutan yang dilakukan TKSK dalam bentuk pelayanan sosial guna memenuhi kebutuhan dasar WRSE yang meliputi pemberdayaan sosial. (UndangUndang Dasar Republik Indonesia No. 11 Tahun 2009 tentang Kesejahteraan Sosial, Pasal 1).

Adapun Tenaga Kesejahteraaan Sosial Kecamatan (TKSK) Kota Kendari dalam penyelenggaraan kesejahteraan sosial adalah:

a. Pada program Kelompok Usaha Bersama (KUBE)

Kube adalah kelompok usaha bersama yaitu salah satu program pemeritah yang ada pada kementriansosial RI khususnya di Direktorat Jenderal Pemberdayaan Sosial dan Penanggulangan kemiskinan yang bertujuan untuk memberdayakan kelompok masyarakat miskin dengan pemberian modal usaha melalui program bantuan langsung. KUBE beranggotakan sepuluh kepala keluarga dari masyarakat miskin yang masuk dalam data terpadu penanganan fakir miskin dan orang tidak mampu.

b. Program Bantuan Pangan Non Tunai (BPNT)

Bantuan Pangan Non Tunai (BPNT) adalah bantuan social pangan dalam bentuk non tunai dari pemerintah yang diberikan kepada kader pembangunan (KPM) setiap bulannya melalui mekanisme akun elektronik yang digunakan hanya untuk membeli bahan pangan di pedagang bahan pangan/ e-warong yang bekerjasama dengan bank.

\section{Faktor Pendukung TKSK dalam pemberdayaan potensi WRSE}

\section{Memberikan kewenangan}

Dinas Sosial Kota Kendari memberikan kewenangan kepada TKSK selaku pihak yang bekerja dilapisan terbawah masyarakat dan merupakan local community organization dalam memberikan pertolongan untuk menanggulangi masalah kesejahteraan sosial yang mereka temui dilapangan.

Menurut (Kartasasmita, 1997:15-17) pemberdayaan masyarakat harus melibatkan segenap potensi yang ada dalam masyarakat. Beberapa aspek diantaranya dapat diketengahkan antara lain, untuk dapat menjalankan misi birokrasinya harus 
ditingkatkan kewenangannya sampai lapisan terendah, ditingkatkan kualitasnya agar benar-benar mampu memberikan bimbingan dan pemberdayaan masyarakat.

\section{Motivasi}

Bertekad untuk mendukung terwujudnya peningkatan kesejahteraan social wanita rawan sosial ekonomi (WRSE) serta membantu menyelenggarakan kesejahteraan social ditingkat kecamatan.

\section{TKSK Melakukan Pendekatan dengan WRSE}

Melakukan pendekatan dengan wanita rawan social ekonomi (WRSE) merupakan peran penting agar tenaga kesejahteraan sosial kecamatan (TKSK) dapat dengan mudah menggali informasi yang menjadi masalah bagi wanita rawan sosial ekonomi tersebut. Pendekatan yang digunakan adalah sebagai berikut:

a. Pendekatan direktif (Instruktif)

Bagi WRSE yang belum berkembang maka kami menggunakan pendekatan direktif.

b. Pendekatan non-direktif (partisipatif)

Bagi WRSE yang sudah mampu mendayagunakan potensi yang dimilikinya perlu didekati dengan pendekatan non-direktif.

\section{Faktor-Faktor penghambat TKSK dalam pemberdayaan potensi WRSE}

\section{Transportasi}

Transportasi menjadi penghambat karena jarak yang jauh dan lokasi yang tidak mendukung menjadi hambatan tenaga kesejahteraan social kecamatan dalam melakukan pemberdayaan sosial.

\section{Ketidak terbukaan WRSE}

Ketidak terbukaan Wanita Rawan Sosial Ekonomi (WRSE) dikarenakan wanita rawan sosial ekonomi (WRSE) tidak ingin memberitahukan status yang dimilikinya.

\section{PENUTUP}

Berdasarkan hasil penelitian yang penulis laksanakan tentang "Peran Tenaga Kesejahteraan Sosial Kecamatan (TKSK) Kota Kendari Dalam Pemberdayaan Potensi Wanita Rawan Sosial Ekonomi” maka dapat ditarik kesimpulan sebagai berikut:Peran TKSK dalam pemberdayaan potensi Wanita Rawan Sosial Ekonomi terdapat empat peran yaitu: Pendataan dan Validasi Basis Data Terpadu (BDT), Mencari Potensi, Melakukan koordinasi dengan pihak dinas sosial, Penyelenggaraan kesejahteraan sosial. 
Namun dalam pemberdayaan potensi Wanita Rawan Sosial Ekonomi, TKSK terkadang mengalami kesulitan atau hambatan dikarenakan WRSE terkesan menyembunyikan data tersebut. Sehingga Tenaga Kesejahtraan Sosial Kecamatan harus menberikan kewenangan, memotivasi, dan melakukan pendekatan kepada Wanita Rawan Sosial Ekonomi.

\section{DAFTAR PUSTAKA}

Gafur, Abdul. (2017). Peran Tenaga Kesejahteraan Sosial Kecamatan Dalam Memfasilitasi Masyarakat Penyandang Masalah Kesejahteraan Sosial (PMKS) Di Kecamatan Tangan-Tangan Aceh Barat Daya. Skripsi. Jurusan Pengembangan Masyarakat Islam Fakultas Dakwah Dan Komunikasi Universitas Negeri Ar-Raniry.

Kartasasmita, Ginanjar. (1997). Pemberdayaan Masyarakat: Konsep Pembangunan Yang Berakar Pada Masyarakat. Yogyakarta: UGM.

Panduan TKSK. (2013). Program Percepatan Dan Perlindungan Sosial (P4S) Dan Bantuan Langsung Sementara Masyarakat (BLSM). Pembangunan Sosial, dan Kajian Sosial.

Peraturan Menteri No. 8 Tahun 2012 Tentang Pedoman Pendataan Dan Pengelolaan Data Penyandang Masalah Kesejahteraan Sosial.

Sugiyono. (2009). Metode Penelitian Kualitatif, dan R\&D. Bandung: Alfabeta.

Undang-Undang RI No. 11 Tahun 2009 Tentang Kesejahteraan Sosial.

Upe, Ambo dan Damsid. (2010). Asas-Asas Multiple Research. Yogyakarta: Tiara Wacana. 